\title{
Biocompatibility, Antioxidant and Anti-Infective Effect of Biosurfactant Produced by Marinobacter litoralis MB15
}

\author{
Ekramul Haque ${ }^{1 *}$, K. Kayalvizhi ${ }^{2}$, Saqib Hassan ${ }^{1}$ \\ 'Department of Microbiology, School of Life Sciences, Pondicherry University, Puducherry, INDIA. \\ ${ }^{2}$ Department of Marine Biotechnology, Bharathidasan University, Tiruchirappalli, Tamil Nadu, INDIA.
}

\begin{abstract}
Objective: In this study, the biosurfactant, produced by a potent nonpathogenic bacterial strain of Marinobacter litoralis MB15 was used for anti-microbial, anti-oxidant and biocompatibility assay. Materials and Methods: Biosurfactant producing bacteria were screened by oil displacement assay and emulsification assay. The best isolate was sequenced by $16 \mathrm{~S}$ rRNA gene analysis. The biosurfactant was produced in modified Zobel marine broth media followed by the recovery of biosurfactant by solvent extraction method. The produced biosurfactant was characterized by using thin layer chromatography, Fourier transform infrared spectroscopy and Electron spray Ionization-Mass Spectroscopy analysis. 1-diphenyl-2-picrylhydrazyl (DPPH) assay, crystal violet assay, 3-(4, 5-dimethylthiazole-2-yl)-2, 5-diphenyltetrazolium bromide) (MTT) assay were performed to determine the anti-oxidant activity, anti-microbial activity and biocompatibility of biosurfactant respectively. Results: The best biosurfactant producing isolate was found to be Marinobacter litoralis. The produced biosurfactant was characterized as rhamnolipid molecules, comprising of both mono $\left(\mathrm{m} / \mathrm{z}=358.98[\mathrm{M}+\mathrm{H}]^{+}\right.$, Rha- $\mathrm{C}_{12: 2} ; \mathrm{m} / \mathrm{z}=543.29[\mathrm{M}+\mathrm{K}]^{+}$, Rha $\left.-\mathrm{C}_{10}-\mathrm{C}_{10}\right)$ and di rhamnolipid homologs $\left(\mathrm{m} / \mathrm{z}=689.34[\mathrm{M}+\mathrm{K}]^{+}\right.$, Rha-Rha-C10-C10). The product showed excellent antimicrobial properties against several
\end{abstract}

pathogens including Candida albicans, Escherichia coli, Vibrio parahaemoIyticus, Bacillus subtilis, S. aureus, Klebsiella pneumonia and Streptococcus pyogenes. The antioxidant activity of biosurfactant was $72.6 \%$ at $5 \mathrm{mg} / \mathrm{ml}$. The biosurfactant showed negligible cytotoxic effect to mouse L292 fibroblastic cell line. Most importantly, after $48 \mathrm{~h}$ of incubation, $84.7 \%$ of cell viability on L292 was observed at $250 \mu \mathrm{g} / \mathrm{ml}$ for biosurfactant. Conclusion: Therefore, this investigation shows the utility of rhamnolipids as noncytotoxic, natural antimicrobial and antioxidant agent for various industrial and biomedical application.

Key words: Marinobacter litoralis, Rhamnolipids biosurfactants, Antimicrobial, Anti-oxidant activity, Biocompatibility.

\section{Correspondence}

Ekramul Haque, Senior Research Fellow, Department of Microbiology, School of Life Sciences, Pondicherry University, Puducherry-605014, INDIA.

Phone: +91 8903947795

Email: hekramul37@gmail.com;

ORCID: http://orcid.org/0000-0002-3729-5303

DOI: 10.5530/ijpi.2020.2.32

\section{INTRODUCTION}

Bacteria are the major group of microorganisms which produce surface active biosurfactant molecule. ${ }^{1}$ Marine microorganisms are capable of producing biosurfactants under extreme environmental conditions, caused by increased UV exposure, changes in salinity, limited nutrients, fluctuation in $\mathrm{pH}$ and temperature. ${ }^{2}$ Marine microbes are reported to release surface active compounds which can emulsify the hydrocarbons in the seawater. The emulsified hydrocarbon can be easily taken up by these microbes as well as non-biosurfactant producing microbes for the source of energy and carbon for their growth. ${ }^{3}$ Marinobacter sp are capable of utilizing hydrocarbon as an energy source by producing surface active molecules. ${ }^{4}$ Production of mono and di rhamnolipid homologs has recently been reported from Marinobacter sp. ${ }^{5}$ Biosurfactants are the amphiphilic sugar molecule which are linked with fatty acids hydrocarbon. ${ }^{6}$ Glycolipids were to have several biological activities, such as antimicrobial, ${ }^{7}$ anti-adhesion ${ }^{8}$ and anti-cancer activity. ${ }^{9}$ The main advantages related to the use of biosurfactants over chemical surfactant includes their higher biodegradability and lower toxicity, as well as their stability at extreme temperature, $\mathrm{pH}$ and salt concentration, in addition to their biocompatibility. ${ }^{10}$ These properties allow them to use in food, cosmetic and pharmaceutical industry. ${ }^{11}$ In the food industry, mainly, microbial biosurfactant use as foaming/emulsifying agent, antioxidant agents, anti-adhesives and stabilizer. ${ }^{12}$ It has also been proved that microbial biosurfactants are the great inhibitor of biofilm formation and microbial adhesion. Biofilms are the microbial communities which adhere to the various abiotic and biotic surfaces. Various food industry and society are facing the daily challenges of microbial biofilms. ${ }^{13}$ In the process of biofilm formation, adhesion is the primary stage and which can be targeted by several anti-adhesive compounds. ${ }^{14}$ Rhamnolipids are the major class of glycolipid biosurfactant mainly produced from Pseudomonas aeruginosa. Due to the pathogenicity of this species, rhamnolipid production is considered as commercially nonviable. Therefore, there is a huge demand in the market for an alternative producer of rhamnolipids, having wide applications in the industry. This study represents an investigation of the biocompatibility, antioxidant and antimicrobial activities of rhamnolipids produced by Marinobacter litoralis MB15 strain.

\section{MATERIALS AND METHODS}

\section{Bacterial Isolation}

Biosurfactant producing bacterial culture were isolated from the seawater of Rock Beach, Pondicherry, India. Approximately, $1 \mathrm{ml}$ of seawater sample was suspended in $9 \mathrm{ml}$ of saline water. The isolation of bacteria was performed by using serial dilution (up to $10^{-8}$ ) technique in $0.95 \%$ sterile saline water. Then, $0.1 \mathrm{ml}$ of every diluted seawater samples was plated on Zobel marine agar (ZMA). Finally, the plates were incubated at $37^{\circ} \mathrm{C}$ for $24-48 \mathrm{~h}$. Pure culture with different morphology were prepared by repetitive streaking on ZMA agar medium and stored at $4^{\circ} \mathrm{C}$. 


\section{Culture conditions}

The cultures were inoculated in $100 \mathrm{ml}$ conical flask containing $25 \mathrm{ml}$ of sterile MZMB (modified Zobel marine broth) medium (g/l): Glucose, 10.000; Yeast extract, 1.000; Peptone, 5.000; Sodium chloride, 19.450; Magnesium chloride, 8.800; Ferric citrate, 0.100; Calcium chloride, 1.800; Potassium chloride, 0.550; Sodium sulphate, 3.240; Sodium bicarbonate, 0.160; Boric acid, 0.022; Ammonium nitrate, 0.0016; Strontium chloride, 0.034; Sodium silicate, 0.004; Sodium fluorate, 0.0024 and cultivated at $30^{\circ} \mathrm{C}, 150 \mathrm{rpm}$ for $16 \mathrm{~h}$ as inoculum.

For the production of biosurfactant, $2 \%(\mathrm{v} / \mathrm{v})$ of inoculum was added into a $250 \mathrm{ml}$ conical flask containing $100 \mathrm{ml}$ of sterile MZMB medium. The medium was then incubated at $30^{\circ} \mathrm{C}, 200 \mathrm{rpm}$ for $168 \mathrm{~h}$. The $\mathrm{pH}$ of the medium was adjusted to 7.0 .

\section{Qualitative assays for the screening of potential biosurfactant producer}

Emulsification assay: The emulsification index of the biosurfactant was determined by adding $2 \mathrm{ml}$ of cell free supernatant into $2 \mathrm{ml}$ of kerosene (1:1) and vortexed vigorously for $2 \mathrm{~min}$. After $24 \mathrm{~h}$ of incubation, the height of the emulsified layer was measured as per the protocol of Bodour et al..${ }^{15}$ All the measurement were carried out in triplicate.

$$
\text { Emulisification index }\left(\mathrm{E}_{24}\right)=\frac{\text { Height of the emulsion layer }}{\text { Total Height }} \times 100
$$

Oil displacement assay: The oil displacement assay was carried out by adding $20 \mathrm{ml}$ of distilled water into a petri dish. Then $20 \mu \mathrm{l}$ of kerosene oil was dropped onto the surface of the water. After that, $10 \mu \mathrm{l}$ of cell free culture broth was added. The area of the clear zone on the oil surface was measured. The distilled water $(10 \mu \mathrm{l})$ was used as a negative control. ${ }^{16}$

\section{Molecular identification of the potent bacterium by $16 \mathrm{~S}$ rDNA gene sequencing}

The most efficient isolate was chosen for the molecular identification. The 16S rDNA gene was amplified by PCR with the universal primer of forward 8F(5'-AGAGTTTGATCCTGGCTCAG-3') and reverse 1942R (5'-GGTTACCTTGTTACGACTT-3') and was directly sequenced. The conditions of PCR were as follows: preheated at $95^{\circ} \mathrm{C}$ for $5 \mathrm{~min}$, then 30 cycles of $94^{\circ} \mathrm{C}$ for $1 \mathrm{~min}$, annealed at $53.8^{\circ} \mathrm{C}$ for $45 \mathrm{sec}$ and extend at $72^{\circ} \mathrm{C}$ for $1 \mathrm{~min}$. Final extension was carried out at $72^{\circ} \mathrm{C}$ for $5 \mathrm{~min}$. The final sequences were aligned and compared with the sequences in the GenBank database of NCBI (National Centre for Biotechnology Information) (http://www.ncbi.nlm.nih.gov) by using BLASTn program. ${ }^{17}$ Phylogenetic tree was constructed by using MEGA software version 6 by neighbor joining method. The sequence of the $16 \mathrm{~S}$ rDNA gene was submitted to GenBank under the accession number of MN055694.

\section{Recovery of biosurfactant}

The culture broth of the MB 15 strain from MZMB medium was centrifuged at $10000 \mathrm{rpm}$ for $15 \mathrm{~min}$ at $4^{\circ} \mathrm{C}$. The cell free broth was acidified to $\mathrm{pH} 2$ by adding $6 \mathrm{~N} \mathrm{HCl}$ and incubated overnight for biosurfactant precipitation at $4^{\circ} \mathrm{C}$. Then equal volume of ethyl acetate was added to the precipitated broth in separating funnel. The mixture was then vigorously shaken for few minutes and allowed to set for phase separation. The organic clear phase (upper phase) was collected in a glass beaker and one spatula of anhydrous sodium sulphate was added into it to remove the remaining water molecule. Finally, the clear solvent was evaporated by using rotary evaporator and the honey color concentrated product was considered as partially purified biosurfactant. The biosurfactant was then lyophilized for further use.

\section{Thin layer chromatography (TLC)}

The extracted biosurfactant was used for thin layer chromatography and it was analyzed on silica plate $60 \mathrm{~F}$ (Merck) with a mobile phase consisting of (chloroform: methanol: water) solvents in the ration of (1.5:2.5:1). The molecules on the silica plate were observed after spraying with the Molisch's reagent and exposed with the iodine vapor for the detection of sugar and lipid molecule present in the biosurfactant respectively.

\section{Fourier transforms infrared spectroscopy (FT-IR)}

FT-IR analysis was carried out to determine the presence of functional group and chemical bond in the extracted biosurfactant. $1 \mathrm{mg}$ of lyophilized biosurfactant molecule was mixed with $100 \mathrm{mg}$ of $\mathrm{KBr}$ and pressed for few seconds to obtain translucent pellets. The spectral analysis was performed in the absorbance mode. The IR spectrum was recorded in the range of $400-4000 \mathrm{~cm}^{-1} .^{18}$

\section{Electron spray ionization mass spectroscopy analysis (ESI-MS)}

Compositional characterization of biosurfactant was carried out by ESI-MS (Agilent 6530 B QTOF). $50 \mu$ of the sample, $(1 \mathrm{mg} / \mathrm{ml}$ in acetonitrile) was applied into the column. Acetonitrile-water $(1: 1)$ was used as mobile phase for this analysis. The flow rate of HPLC was $0.2 \mathrm{ml} / \mathrm{min}$ and directly applied into the spectrometer. Mass spectrometric condition were as follow: Gas temperature $300^{\circ} \mathrm{C}$, Capillary voltage $3500 \mathrm{~V}$, Fragments voltage $175 \mathrm{~V}$, Nebulizer flow rate $8 \mathrm{ml} / \mathrm{min}$. Mass spectrometer was operating on positive mode (ESI+) and the ionization method was used over the mass range of $50-800 \mathrm{~m} / \mathrm{z}$.

\section{Antimicrobial assay}

The following clinical pathogens, kindly provided by the department of Microbiology, PIMS, Puducherry (India), were used in the antimicrobial assays: Streptococcus pyogenes, S. aureus, Bacillus subtilis, Klebsiella pneumoniae, Vibrio parahaemolyticus, Candida albicans, E.coli. All these cultures were grown in Trypticase Soy Broth (TSB) at $37^{\circ} \mathrm{C}$ in aerobic conditions (overnight) except Candida albicans. Yeast mould broth (YMB) was used to grow Candida albicans at $30^{\circ} \mathrm{C}$. All the cultures were preserved at $-80^{\circ} \mathrm{C}$ in suitable culture broth supplemented with $20 \%$ $(\mathrm{v} / \mathrm{v})$ glycerol until used. The antimicrobial activity of biosurfactants of Marinobacter litoralis MB15 strains against several microbial pathogens was measured as per the protocol described by Gudina et al. ${ }^{7}$ Briefly, in this method (micro-dilution) 96-well plate was used. For each culture suitable media and condition were used (as described earlier). Briefly, $125 \mu \mathrm{l}$ of sterile broth was kept in the first well and $125 \mu \mathrm{l}$ of broth in the remaining wells. Later, $125 \mu$ of biosurfactant solution in phosphate buffer saline (10 mM K $\mathrm{HPO}_{4 /} \mathrm{KH}_{2} \mathrm{PO}_{4}$ and $\left.150 \mathrm{mM} \mathrm{NaCl}, \mathrm{pH} 7.0\right)$ at a $200 \mu \mathrm{g} / \mathrm{ml}$ concentration were kept into the $1^{\text {st }}$ column and mixed with the culture broth. As a result, the concentration of the biosurfactant became $100 \mu \mathrm{g} / \mathrm{ml}$. In a serial manner, $125 \mu \mathrm{l}$ were added to the following wells, throwing $125 \mu \mathrm{l}$ of the mixture from the $10^{\text {th }}$ column, as a result the total volume $(125 \mu \mathrm{l})$ in each well remains fixed. Negative control and growth control did not have any biosurfactant and assigned in columns 11 and 12 respectively. Overnight grown culture $(2.5 \mu \mathrm{l})$ was added into all the wells were under defined optimal conditions and diluted to $10^{8} \mathrm{cfu} / \mathrm{ml}$. The $11^{\text {th }}$ column did not contain culture. The plates were incubated for $48 \mathrm{~h}$ under suitable conditions for each pathogen. For every strain, triplicate assays were carried out for all the concentration of biosurfactant. The absorbance at $600 \mathrm{~nm}$ was measured for each well after $48 \mathrm{~h}$ of incubation. The growth inhibition percentages at various concentrations of biosurfactant for each pathogen were measured as Eq. (1): Growth inhibition $_{c}(\%)=\left[1-\left(\mathrm{A}_{c} / \mathrm{A}_{0}\right) \times 100\right]$ 
Where $A_{c}$ indicates the O.D of the well with sample and $A_{0}$ is the O.D of the control well, with no biosurfactant.

\section{DPPH assay for anti-oxidant activity of biosurfactant}

1,1-diphenyl-2-picrylhydrazyl (DPPH) radical scavenging assay for biosurfactant solution was performed as per the protocol described by Turkmen et al. ${ }^{19}$ with necessary modification. In this experiment, $0.5 \mathrm{ml}$ of methanolic solution of different concentration of biosurfactant between 1 to $5 \mathrm{mg} / \mathrm{ml}$ was mixed with $2.5 \mathrm{ml}$ of $0.5 \mathrm{mM}$ DPPH methanolic solution. Then the mixed solution was vigorously shaken and kept for $30 \mathrm{~min}$ incubation in dark at room temperature. The optical density (O.D) was measured at $517 \mathrm{~nm}$ by using UV-Vis spectrophotometer. Ascorbic acid was used in this assay as a positive control, methanol was set as blank and the assays were carried out in triplicates. The scavenging capacity of $\mathrm{DPPH}(\%)$ was measured by using the formula below:

$\%$ of inhibition $=\frac{(\text { absorbance in control }- \text { absorbance in sample })}{\text { absorbance in control }} \times 100$

\section{Biocompatibility assay: MTT assay}

\section{Cell lines and culture conditions}

DMEM cell culture media were purchased from Invitrogen, USA; FBS (fetal bovine serum) antibiotic-antimycotic solutions were from Himedia, India. The cell line L292 were collected from NCCS Pune, India (National Centre for Cell Science). The cells were maintained in DMEM media supplemented with L-glutamine, $10 \% \mathrm{FBS}$ and streptomycin-penicillin solution to a final concentration of $100 \mu \mathrm{g} / \mathrm{ml}$ streptomycin and $100 \mathrm{I} . \mathrm{U} . / \mathrm{ml}$ penicillin at $37^{\circ} \mathrm{C}, 5 \% \mathrm{CO}_{2}$ in $95 \%$ humidified air. In the tissue culture flask, routine sub culturing technique was performed to maintain the cells. In every $48 \mathrm{~h}$, the medium of the culture was changed and the cells were passaged when they reached in the stage of confluency.

The toxicity level of biosurfactant was measured using a conversion assay of MTT (3-(4, 5-dimethylthiazole-2-yl)-2, 5-diphenyltetrazolium bromide) dye against L292 cell line as per the protocol described by Patowary et al. ${ }^{20}$ with necessary modifications. 96-well flat-bottomed plates were seeded at approximately $6 \times 10^{3}$ cells per well with L292 actively growing in complete DMEM and incubated at $37^{\circ} \mathrm{C}, 5 \% \mathrm{CO}_{2}$. Five different concentrations of the biosurfactant (250, 200, 150, 100 and $50 \mu \mathrm{g} / \mathrm{ml}$ ) prepared in serum-free DMEM were used to treat cultured cells. Biosurfactant was added in wells in triplicates and it was incubated for $0 \mathrm{~h}, 24 \mathrm{~h}$ and $48 \mathrm{~h}$. A control, i.e., only DMEM (without the addition of biosurfactant) was also used for comparison. $20 \mu \mathrm{L}$ of $5 \mathrm{mg} / \mathrm{mL}$ MTT was added to all the wells after the incubation period and incubated at $37^{\circ} \mathrm{C}$. After $6 \mathrm{~h}$, the liquid content of each well was decanted and $100 \mu \mathrm{L}$ of dimethyl sulfoxide was administrated to solubilize the purple formazan crystals. The absorbance of the plate was measured after a brief incubation in a UV-Vis well plate reader at $570 \mathrm{~nm}$. The cell viability in percentage was measured based on the following formulae-

$$
\text { Cell viability }(\%)=\mathrm{N}_{\mathrm{t}} / \mathrm{N}_{\mathrm{c}} \times 100
$$

where, $\mathrm{N}_{\mathrm{t}}$ indicates the optical density of the biosurfactant treated cells, whereas $\mathrm{N}_{\mathrm{c}}$ is the optical density of the untreated control cells.

\section{Statistical analysis}

All the statistical analysis was performed by using OriginPro software (version 8.5, Originlab Corporation, Northampton, USA).

\section{RESULTS}

\section{Screening and identification of biosurfactant producing microorganism}

A few biosurfactants producing bacterial cultures were isolated from seawater, rock beach, Pondicherry, India. Based on the qualitative assays such as oil displacement assay and emulsification index, one of the best isolates for the production of biosurfactant was chosen for further analysis (Table 1). The bacterial isolate selected was assigned as MB15. In order to identify this isolate, the genotypic analysis based on partial $16 \mathrm{~S}$ rDNA gene sequencing, was performed to find out the exact taxonomic position of the bacterial strain. The $16 \mathrm{~S}$ rDNA sequences alignment of MB15 with the sequences obtained from the BLASTn search shown $99 \%$ similarity to the Marinobacte rlitoralis. (Figure 1) The sequence was submitted to the NCBI and the accession number obtained was MN055694.

\begin{tabular}{l}
$\begin{array}{l}\text { Table 1: Qualitative assays for the biosurfactant production. All the } \\
\text { experiments were carried out in triplicate and the values were presented } \\
\text { as mean } \pm \text { SD }(\mathbf{n = 3}) \text {. }\end{array}$ \\
\hline \begin{tabular}{ccc} 
Isolate & Oil displacement activity \\
$(\mathrm{mm})$ & $\begin{array}{c}\text { Emulsification activity } \\
\left(\mathrm{E}_{24}\right)(\%)\end{array}$ \\
\hline MB11 & $4.1 \pm 0.13$ & $62 \pm 1.34$ \\
MB15 & $5.7 \pm 0.21$ & $75 \pm 1.23$ \\
MB17 & $3.9 \pm 0.21$ & $58 \pm 2.23$ \\
MB 18 & $4.1 \pm 0.20$ & $63 \pm 1.45$ \\
MB19 & $4.4 \pm 0.12$ & $65 \pm 1.42$ \\
MB21 & $3.5 \pm 0.11$ & $54 \pm 2.27$ \\
\hline
\end{tabular}
\end{tabular}

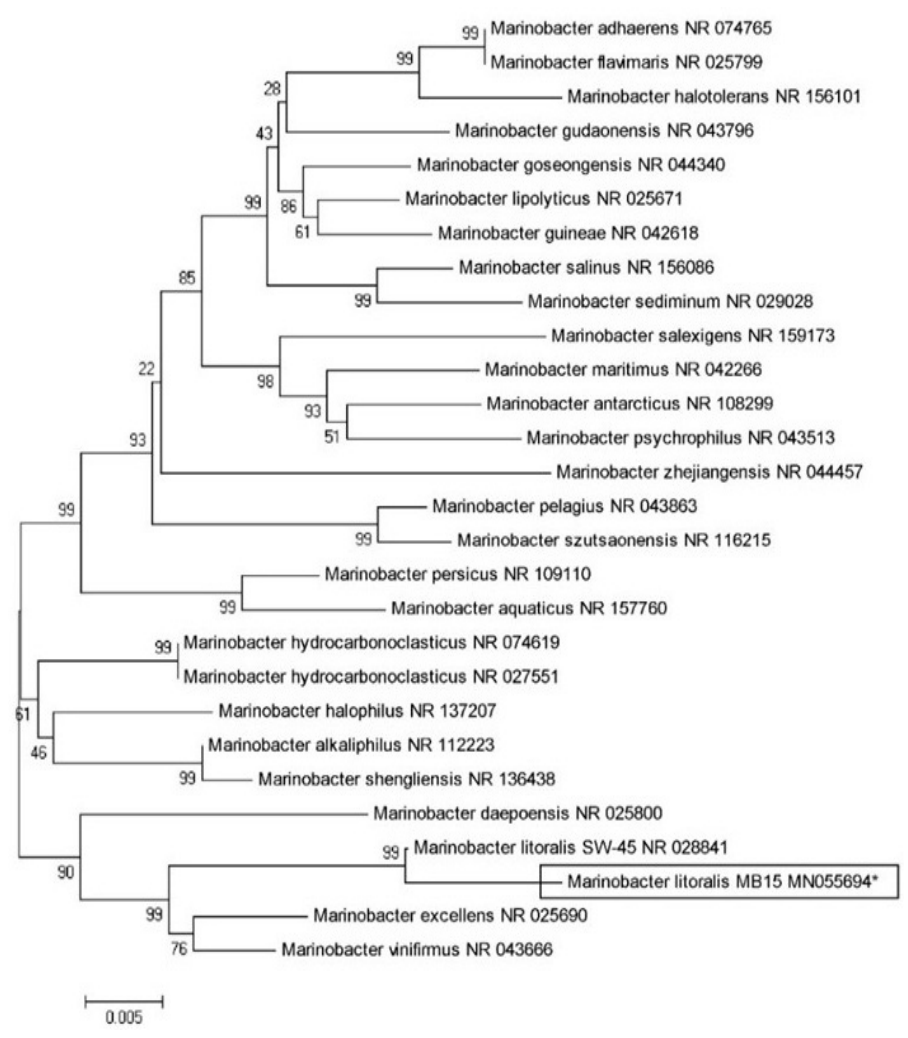

Figure 1: Phylogenetic relationship between the Marinobacter litoralis MB15 and other strains or species based on the homology of $16 \mathrm{~S}$ rDNA sequences. 
Thin layer chromatography (TLC) and Fourier transform infrared spectroscopy (FT-IR) analysis

Thin layer chromatography analysis helps to separate and identify the chemical components present in solution. The biosurfactant showed yellow spot on the plate upon exposure to iodine vapor, suggesting the presence of lipid molecule. Treatment with Molisch's reagent revealed purple color spot suggesting the presence of sugar molecule. The spots were observed at the same position on the plate for both the tests suggested that the sample is a glycolipid molecule. The FTIR spectrum of biosurfactant was measured for the detection of functional groups, in the spectral area of $400-4000 \mathrm{~cm}^{-1}$ (Figure 2). The peak at $1726 \mathrm{~cm}^{-1}$ denotes the presence of carbonyl ester bond in the molecule. The presence of stretching of COO-group was found at $1654 \mathrm{~cm}^{-1}$. The absorption peak for (C-O-C) bond (glycosidic bond) present in the biosurfactant molecule was found at $1069 \mathrm{~cm}^{-1}$. A broad band was observed at $3406 \mathrm{~cm}^{-1}$, for the presence of hydroxyl $(-\mathrm{OH})$ group in the molecule. The presence of C- $\mathrm{H}$ bands $\left(\mathrm{CH}_{2}-\mathrm{CH}_{3}\right)$ was observed at $2927 \mathrm{~cm}^{-1}$ and $2856 \mathrm{~cm}^{-1}$.

\section{Electron spray ionization mass spectroscopy analysis}

The structural characterization of biosurfactant produced by Marinobacter litoralis MB15 showed the presence of at least three major rhamnolipid homologs. These three prominent peaks were observed at $\mathrm{m} / z$ 359.27, $m / z 543.29, m / z 689.34$. (Figure 3). These peaks represents, $m / z=358.98$ $[\mathrm{M}+\mathrm{H}]^{+}$, Rha- $\mathrm{C}_{12: 2} ; m / z=543.29[\mathrm{M}+\mathrm{K}]^{+}, \mathrm{Rha}-\mathrm{C}_{10}-\mathrm{C}_{10} ; \mathrm{m} / z=689.34$ $[\mathrm{M}+\mathrm{K}]^{+}$,Rha-Rha-C10-C10. A predominant dirhamnolipid homologs, Rha-Rha-C10-C10 along with other rhamnolipid congeners from

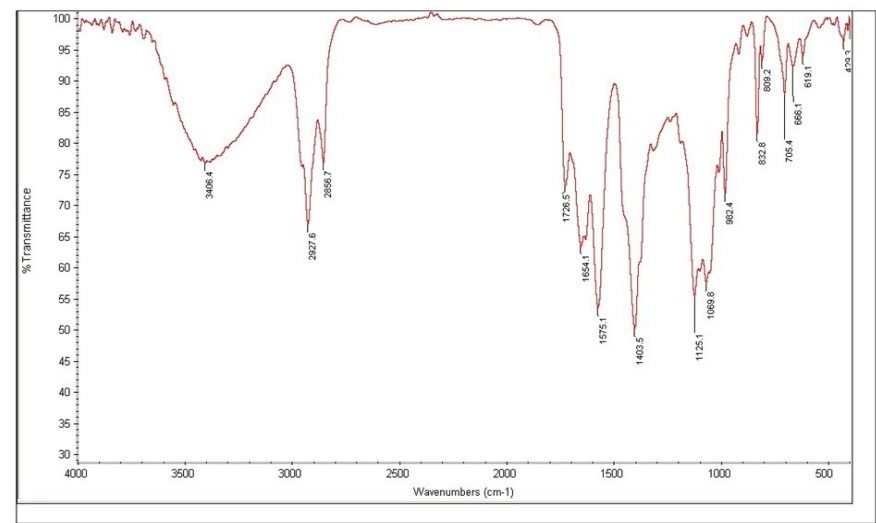

Figure 2: FT-IR spectrum of the biosurfactant.

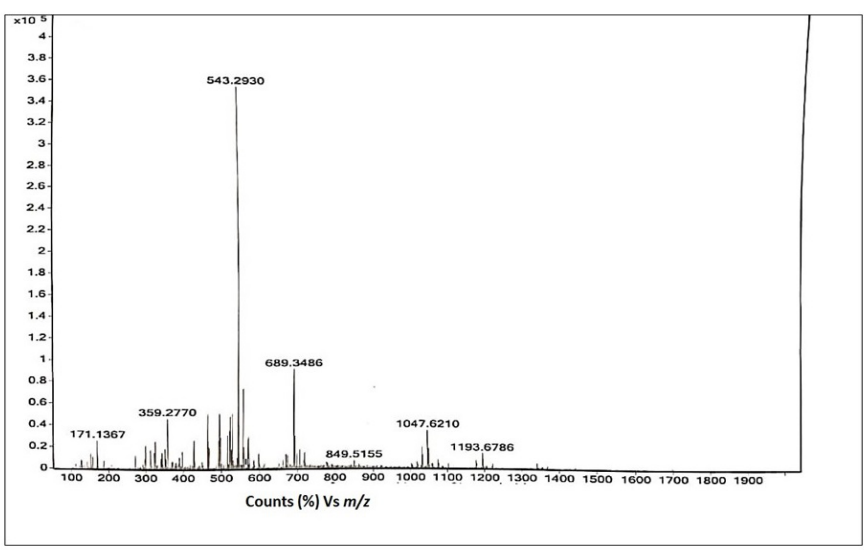

Figure 3: ESI-MS analysis of the biosurfactant.
Marinobacter sp was reported elsewhere. ${ }^{5}$ In our study, Marinobacter litoralis MB15 found to be the producer of predominant mono rhamnolipid, Rha $-\mathrm{C}_{10}-\mathrm{C}_{10}$.

\section{Anti-microbial activity}

The antimicrobial activities of the biosurfactant was evaluated against certain clinical pathogens (Figure 4). It was found that the concentration range $(25-100 \mu \mathrm{g} / \mathrm{ml})$ of biosurfactant, showed $100 \%$ inhibition against Streptococcus pyogenes and Klebsiella pneumoniae. Although the growth inhibition for Streptococcus pyogenes and Klebsiella pneumonia was achieved at a concentration of $25 \mu \mathrm{g} / \mathrm{ml}$ itself. Whereas at $50-100 \mu \mathrm{g} / \mathrm{ml}$ concentration it showed a growth inhibition of $100 \%$ against S. aureus, Vibrio parahaemolyticus and Candida albicans. However, the growth inhibition for S. aureus, Vibrio parahaemolyticus and Candida albicans was achieved at $50 \mu \mathrm{g} / \mathrm{ml}$ itself. The lowest concentration $(100 \mu \mathrm{g} / \mathrm{ml})$ of biosurfactant exhibited $100 \%$ inhibition against Bacillus subtilis. The lowest anti-bacterial activity was found against $E$. coli $(58 \%)$ at $100 \mu \mathrm{g} / \mathrm{ml}$. The anti-microbial activity was proportional to the biosurfactant concentration for all strains tested. In our study we found that at $25-100 \mu \mathrm{g} / \mathrm{ml}$ of glycolipid concentration inhibits the growth of the gram negative, gram positive bacteria and yeast.

\section{1-diphenyl-2-picrylhydrazyl (DPPH) free radical scavenging assay}

The DPPH free radical assay has been widely used for determining the free radical scavenging activities of antioxidants. The DPPH activity of the rhamnolipid biosurfactants from MB15 was compared with the control ascorbic acid (Figure 5). A concentration dependent scavenging activity of biosurfactant was measured and the maximum activity was observed at $5 \mathrm{mg} / \mathrm{ml}$.

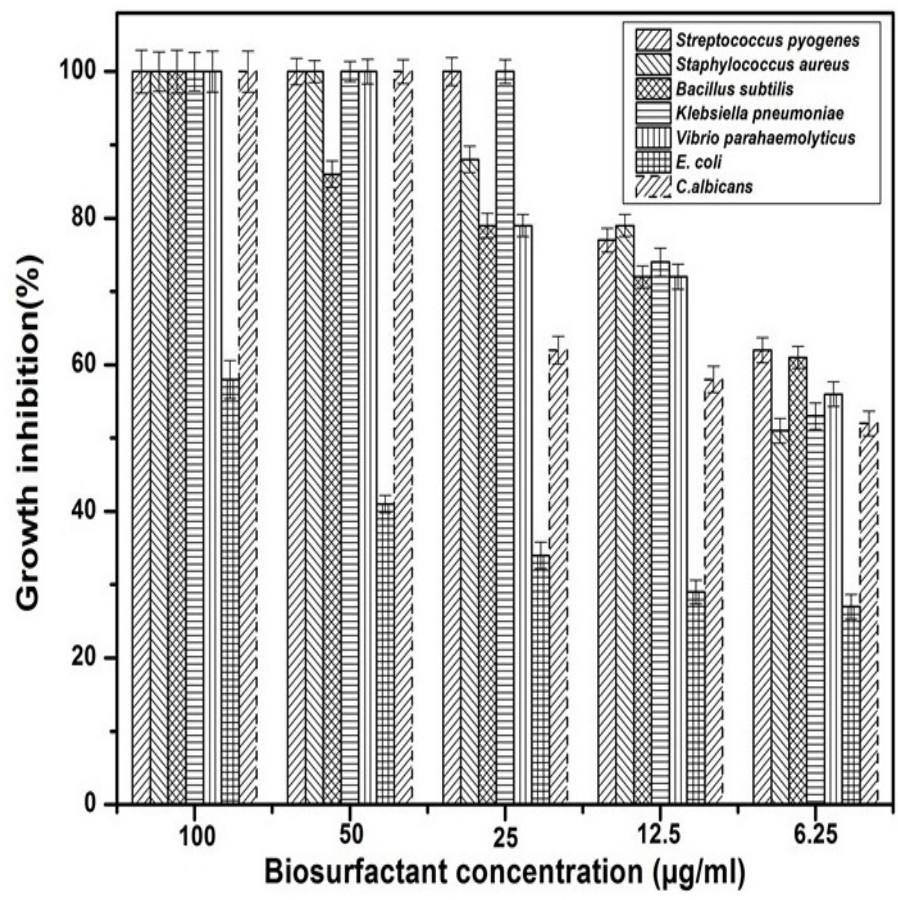

Figure 4: Antimicrobial activity spectrum of the biosurfactant. All the experiments were carried out in triplicate and the values were presented as mean $\pm \mathrm{SD}(n=3)$ 


\section{Biocompatibility assay}

To evaluate the toxicity of biosurfactant, we treated mouse L292 fibroblastic cell line at increasing doses of biosurfactant for $0 \mathrm{~h}, 24 \mathrm{~h}$ and $48 \mathrm{~h}$ followed by an MTT conversion assay. As shown in Figure 6, biosurfactant exhibited negligible toxicity up to $250 \mu \mathrm{g} / \mathrm{ml}$ (highest conc.). While $100 \%$ of the cell viability was reached in case of control. After $48 \mathrm{~h}$ of incubation,

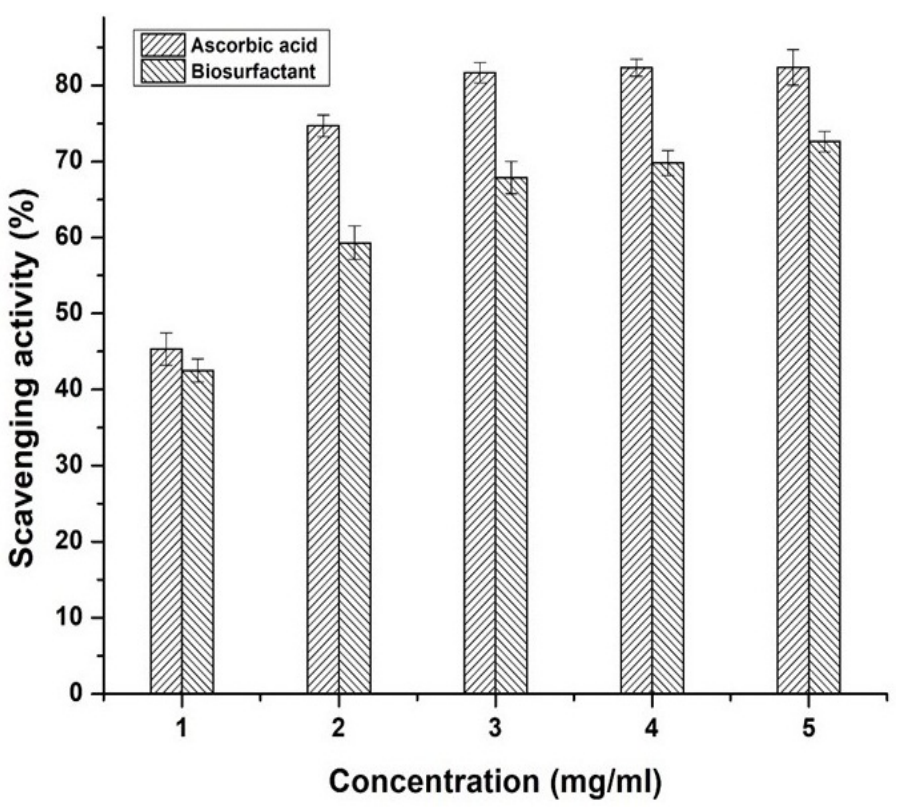

Figure 5: Scavenging effect on DPPH free radical by biosurfactant and ascorbic acid. All the experiments were carried out in triplicate and the values were presented as mean \pm SD $(n=3)$.

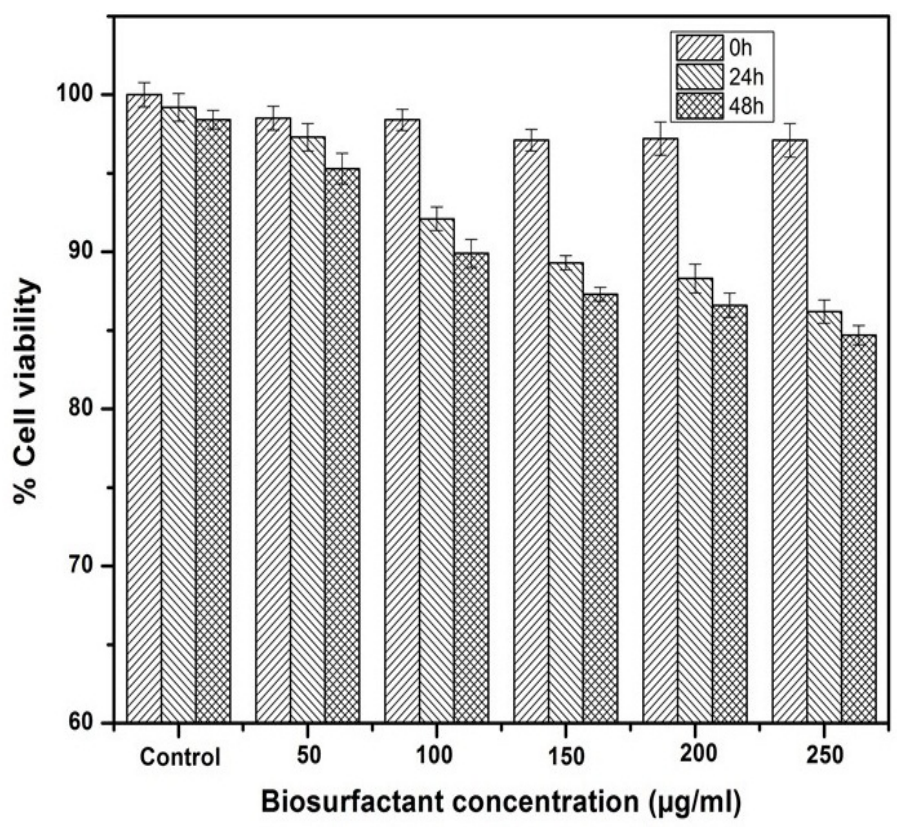

Figure 6: Cytotoxicity of different doses of biosurfactant upon treating the L292 cell line in terms of the cell viability percentage. All the experiments were carried out in triplicate and the values were presented as mean \pm SD $(n=3)$.
$84.7 \%$ of cell viability on L292 was observed at $250 \mu \mathrm{g} / \mathrm{ml}$ (maximum concentration) for biosurfactant.

\section{DISCUSSION}

Bacterial isolates from sea water were screened for their ability to produce biosurfactant based on their oil displacement activity and emulsification index. The produced biosurfactant was found to be glycolipid molecules based on the preliminary characterizations. ${ }^{21}$ The IR-peaks were commonly found in glycolipid biosurfactant produced by several bacterial species. ${ }^{22}$ Furthermore, the intensive characterization revealed that the biosurfactant produced from Marinobacter litoralis MB15 was a mixture of mono and di rhamnolipids homologs. The production pattern of rhamnolipid homologs by this isolate was quite similar to the rhamnolipid homologs which have shown to be produced by both Pseudomonas aeruginosa and marine Pseudomonas sp. MCTG214(3b1). ${ }^{23}$ The biosurfactant showed remarkable anti-microbial and anti-oxidant activity. These findings clearly indicate that glycolipid biosurfactant has a promising future in the biomedical field as an antimicrobial agent. Haba et al..$^{24}$ reported that glycolipid biosurfactant produced from Pseudomonas aeruginosa exhibited significant inhibition against Klebsiella pneumonia, Staphylococcus aureus, Streptococcus faecalis, Bacillus subtilis, Proteus vulgaris, Candida albicans. These results are also concurrence with the existing reports regarding the anti-microbial activity of glycolipid biosurfactant from different bacterial species. ${ }^{25}$ In addition, it may also be used as a co-preservative in various product formulations which may reduce the use of synthetic preservatives. The biosurfactant showed excellent anti-oxidant activity. Antioxidant property is a crucial feature of food products as it is effective against degenerative diseases and coronary heart diseases. The antioxidant activity of rhamnolipid at $5 \mathrm{mg} / \mathrm{ml}$ was $72.6 \%$ which was higher than the activity of mannosyl erythritol lipid which showed $50.3 \%$ at $10 \mathrm{mg} / \mathrm{ml} .{ }^{26}$ Finally, it was observed that biosurfactant is less toxic over L292 normal cells line and may serve as a reference for non-toxic biosurfactant that can be used as a potent biological molecule in the field of biological interfaces. This result also confirms the possible utility of this glycolipid biosurfactant which acquire safety standards for living organism. According to ISO report, the cell viability greater than $80 \%$ may be considered as non-toxic. ${ }^{27}$

\section{CONCLUSION}

Marinobacter litoralis MB15, isolated from the marine environment, has the capability to synthesize mono and di rhamnolipid homologs. To the best of our knowledge, production of rhamnolipid has not been previously reported by this strain. The rhamnolipid biosurfactants produced by MB15 showed excellent antioxidant, antimicrobial activity. In addition, biosurfactant also revealed negligible cytotoxic effect to L292 cell line. Therefore, the results obtained suggest the probable application of glycolipid as an effective antimicrobial as well as antioxidant agent to minimize the bacterial adhesion and formation of biofilm in the field of food and biomedical industry.

\section{ACKNOWLEDGEMENT}

The authors are extremely thankful to the Department of Biotechnology, Ministry of Science and Technology, New Delhi. Ekramul Haque is grateful to UGC, New Delhi for the Maulana Azad National Fellowship. (Award Letter No. F1-17.1/2014-15/ MANF-2014-15-MUS-WES-48033/ (SAIII/ Website).

\section{CONFLICT OF INTEREST}

All the authors declare that there is no conflict of interest. 


\section{ABBREVIATIONS}

DPPH: 1-diphenyl-2-picrylhydrazyl; MTT:(4, 5-dimethylthiazole-2-yl)-2, 5-diphenyltetrazolium bromide); TLC: Thin layer chromatography; FT-IR: Fourier transform infrared spectroscopy; ESI-MS: Electron spray Ionization-Mass Spectroscopy; ZMA: Zobel marine agar; MZMB: Modified Zobel marine broth; PCR: Polymerase chain reaction; NCBI: National Centre for Biotechnology Information; BLAST: Basic local alignment search tool; TSB: Trypticase Soy Broth; YMB: Yeast mould broth; FBS: Fetal bovine serum; NCCS: National Centre for Cell Science; DMEM: Dulbecco's Modified Eagle Medium.

\section{REFERENCES}

1. Femi-Ola TO, Oluwole OA, Olowomofe TO, Yakubu H. Isolation and screening of biosurfactant-producing bacteria from soil contaminated with domestic waste water. BJES. 2015;3(1):58-63.

2. Bijlsma R, Loeschcke V. Environmental stress, adaptation and evolution: An overview. J Evol Biol. 2005;18(4):744-9.

3. DeAlmeida DG, DaSoares SRDCF, Luna JM, Rufino RD, Santos VA, Banat IM et al. Biosurfactants: Promising molecules for petroleum biotechnology advances. Front Microbiol. 2016;7:1718.

4. Bonin P, Vieira C, Grimaud R, Militon C, Cuny P, Lima O, et al. Substrates specialization in lipid compounds and hydrocarbons of Marinobacter genus. Environ Sci Pollut Res Int. 2015;22(20):15347-59

5. Tripathi L, Twigg MS, Zompra A, Salek K, Irorere VU, et al. Biosynthesis of rhamnolipid by a Marinobacter species expands the paradigm of biosurfactant synthesis to a new genus of the marine microflora. Microb Cell Fact. 2019:18(1):164.

6. Banat IM, Franzetti A, Gandolfi I, Bestetti G, Martinotti MG, Fracchia L, et al. Microbial biosurfactants production, applications and future potential. Appl Microbiol Biotechnol. 2010;87(2):427-44.

7. Gudiña EJ, Rocha V, Teixeira JA, Rodrigues LR. Antimicrobial and antiadhesive properties of a biosurfactant isolated from Lactobacillus paracasei ssp. paracasei A20. Lett Appl Microbiol. 2010;50(4):419-24.

8. DeCortes-Sanchez AJ, Hernandez-Sanchez H, Jaramillo-Flores ME. Biological activity of glycolipids produced by microorganisms: New trends and possible therapeutic alternatives. Microbiol Res. 2013;168(1):22-32.

9. Zhao X, Geltinger C, Kishikawa S, Ohshima K, Murata T, Nomura N, et al Treatment of mouse melanoma cells with phorbol 12-myristate 13-acetate counteracts mannosylerythritol lipid-induced growth arrest and apoptosis. Cytotechnol. 2000;33(1-3):123-30

10. Zheng $C$, Wang M, Wang Y, Huang Z. Optimization of biosurfactant-mediated oil extraction from oil sludge. Bioresour Technol. 2012;110:338-42.

11. Md F. Biosurfactant: production and application. J Pet Environ Biotechnol. 2012;3(4):124.
12. Dalili D, Amini M, Faramarzi MA, Fazeli MR, Khoshayand MR, Samadi N. Isolation and structural characterization of Coryxin, a novel cyclic lipopeptide from Corynebacterium xerosis NS5 having emulsifying and anti-biofilm activity. Colloids and Surfaces B. 2015;135:425-32

13. Sadekuzzaman M, Yang S, Mizan MFR, Ha SD. Current and recent advanced strategies for combating biofilms. Compr Rev Food Sci F. 2015;14(4):491-509.

14. Janek T, Łukaszewicz M, Krasowska A. Antiadhesive activity of the biosurfactant pseudofactin II secreted by the Arctic bacterium Pseudomonas fluorescens BD5. BMC Microbiol. 2012;12(1):24.

15. Bodour AA, Guerrero-Barajas C, Jiorle BV, Malcomson ME, Paull AK, Somogyi A, et al. Structure and characterization of flavolipids, a novel class of biosurfactants produced by Flavobacterium sp. strain MTN11. Appl Environ Microbiol. 2004:70(1):114-20.

16. Rodrigues LR, Teixeira JA, DerMei HCV, Oliveira R. Physicochemical and functional characterization of a biosurfactant produced by Lactococcus lactis 53. Colloids and Surfaces B. 2006;49(1):79-86.

17. Zhang Z, SchwartzS, Wagner L, Miller W. A greedy algorithm for aligning DNA sequences. J Comput Bio. 2000:7(1-2):203-14.

18. Heyd M, Kohnert A, Tan TH, Nusser M, Kirschhöfer F, Brenner-Weiss G, et al. Development and trends of biosurfactant analysis and purification using rhamnolipids as an example. Anal Bioanal Chem. 2008;391(5):1579-90.

19. Turkmen N, Sari F Velioglu YS. Effects of extraction solvents on concentration and antioxidant activity of black and black mate tea polyphenols determined by ferrous tartrate and Folin-Ciocalteu methods. Food Chem. 2006;99(4):835-41.

20. Patowary K, Patowary R, Kalita MC, Deka S. Characterization of biosurfactant produced during degradation of hydrocarbons using crude oil as sole source of carbon. Front Microbiol. 2017:8:279.

21. Varjani SJ, Upasani VN. Core flood study for enhanced oil recovery through ex-situ bioaugmentation with thermo-and halo-tolerant rhamnolipid produced by Pseudomonas aeruginosa NCIM 5514. Bioresour Technol. 2016a;220:175-82.

22. Varjani SJ, UpasaniVN. Carbon spectrum utilization by an indigenous strain of Pseudomonas aeruginosa NCIM 5514: Production, characterization and surface-active properties of biosurfactant. Bioresour Technol. 2016;221:510-16.

23. Abdel-Mawgoud AM, Lépine F, Déziel E. Rhamnolipids: Diversity of structures, microbial origins and roles. Appl Microbiol Biotechnol. 2010;86(5):1323-36.

24. Haba E, Pinazo A, Jauregui O, Espuny MJ, Infante MR, Manresa A. Physicochemical characterization and antimicrobial properties of rhamnolipids produced by Pseudomonas aeruginosa 47T2 NCBIM 40044. Biotechnol Bioeng. 2003;81(3):316-22.

25. Vatsa P, Sanchez L, Clement C, Baillieul F, Dorey S. Rhamnolipid biosurfactants as new players in animal and plant defense against microbes. Int $\mathrm{J} \mathrm{Mol} \mathrm{Sci.}$ 2010:11(12):5095-108

26. Takahashi M, Morita T, Fukuoka T, Imura T, Kitamoto D. Glycolipid biosurfactants, mannosyl erythritol lipids, show antioxidant and protective effects against $\mathrm{H}_{2} \mathrm{O}$-induced oxidative stress in cultured human skin fibroblasts. JOleo Sci. 2012;61(8):457-64.

27. Standardization IOF. Biological Evaluation of Medical Devices-Part 5: Tests for In vitro Cytotoxicity. ISO: Geneva, Switzerland. 2009.

Article History: Submission Date : 20-03-2020; Revised Date : 16-04-2020; Acceptance Date : 09-05-2020.

Cite this article: Haque E, Kayalvizhi K, Hassan S. Biocompatibility, Antioxidant and Anti-Infective Effect of Biosurfactant Produced by Marinobacter litoralis MB15. Int. J. Pharm. Investigation. 2020;10(2):173-8. 